\title{
The Problem of the Aging Surgeon
}

\section{When Surgeon Age Becomes a Surgical Risk Factor}

Ralph B. Blasier MD, JD

Published online: 31 October 2008

(C) The Association of Bone and Joint Surgeons 2008

\begin{abstract}
The question of when a surgeon should retire has been the subject of debate for decades. Both anecdotal evidence and objective testing of surgeons suggest age causes deterioration in physical and cognitive performance. Medical education, residency and fellowship training, and technology evolve at a rapid pace, and the older a surgeon is, the more likely it is he or she is remote from his or her initial education in his or her specialty. Research also shows surgeons are reluctant to plan for retirement. Although there is no federally mandated retirement age for surgeons in the United States, surgeons must realize their skills will decline, a properly planned retirement can be satisfying, and the retired surgeon has much to offer the medical and teaching community.
\end{abstract}

\section{Introduction}

Is there an age beyond which the surgeon's age becomes an unacceptable part of the risk of surgery?

"II would not mind being operated on by a surgeon of 91.' -Dr Michael DeBakey at 91" [2].

Surgeons age. Everyone ages. Is there a problem? Observation during daily living discloses that, with advancing age, human physical prowess declines. For a while, advancing age is accompanied by increasing

The author certifies that he or she has no commercial associations (eg, consultancies, stock ownership, equity interest, patent/licensing arrangements, etc) that might pose a conflict of interest in connection with the submitted article.

R. B. Blasier ( $\square)$

Department of Orthopaedic Surgery, Wayne State University, 6071 West Outer Drive, Detroit, MI 48235, USA

e-mail: rblasier@dmc.org wisdom; however, eventually even mentation declines. However, is there evidence that increasing surgeon age makes difficult surgery more difficult or risky surgery riskier? Consider the following true anecdotes.

An elderly surgeon, after a day performing surgery, turns to his younger colleague and asks, "Bill, please take me to my office. I don't know where it is" [8].

A pioneer of joint replacement surgery, in his late $80 \mathrm{~s}$, continues to expound about his great surgical skills to all who will listen and continues to perform surgery, but routinely his younger colleagues must be called in to finish his operations when he cannot finish them himself [this is a case I personally observed]. He experiences technical difficulty as a result of his own age-impaired vision, and he displays occasional serious lapses in judgment.

At a major Midwest university hospital, a universally revered mentor of a generation of surgeons never really progressed in his skills from open abdominal surgery to laparoscopic abdominal surgery [3]. He continued to operate, however, including performing operations laparoscopically. One day, he got into more trouble than he could get out of, and a patient bled to death on the operating table during a routine gallbladder operation. The hospital investigated the situation. Investigators found that for 6 years, the clerks who schedule surgery had routinely been ordering extra blood to be set up for possible transfusion on this surgeon's laparoscopic surgeries, because they knew his operations were abnormally bloody. Similarly, investigators found that for years, the anesthesia department had been routinely adjusting their schedules so as to put the most experienced anesthesiologists in this surgeon's operating room because they knew his surgical risks were greater. However, no one had ever pointed this out to the surgeon or to other hospital officials. The reverence that all observers had for this icon of surgical 
education was too great for anyone to point out the obvious until a death ensued.

\section{Only Wine and Cheese Improve With Age}

The anecdotes recounted here are all true. The fact that these events occurred suggests there is a problem posed by the loss of skills by aging surgeons. However, this problem has attracted only scant interest and little study. A notable exception is Lazar J. Greenfield, Chair of the Department of Surgery at the University of Michigan from 1987 to 2002, who has had a teaching and research interest in the problem of the aging surgeon.

Greenfield and Proctor [10] summarize the physiological processes of aging as (1) wear and tear or (2) programmed cell death [10]. Wear and tear can include mechanical damage to structures that are only imperfectly repaired. Programmed cell death refers to the emerging understanding that the somatic cells are limited from the time of fertilization to only approximately six to 15 generations of mitoses. After that limit, further cell division is impossible, and injured or worn out cells no longer can be replaced.

Knowledge and experience remain for a long time. First to go is strength, then eyesight, then dexterity, and finally cognition [10, 18, 19]. Knowledge, experience, and reputation can compensate for a long time. The declines are gradual. The surgeon and his or her colleagues may not notice the changes until the deficits become serious.

\section{Remoteness of Education}

When contemplating the effect of age on surgeons, quantity of education, remoteness of education, and obsolescence of the content of the education are all at least theoretical concerns. As an example of quantitative difference, orthopaedic surgeons entering postdoctorate specialty education before 1979 obtained an average of 4 years of residency education after medical school. Now, the average postdoctorate specialty education in orthopaedic surgery is 5.5 years. Before 1979, an accredited allopathic residency in orthopaedic surgery was 4 years, and postresidency fellowship education was distinctly rare. Now, an accredited allopathic residency in orthopaedic surgery must be 5 years, and postresidency fellowship education is quite common with approximately half of residency graduates taking a 1-year fellowship after residency. Other surgical specialties have changed in similar ways. To generalize, the older a surgeon is, the more likely he or she is to have had a shorter initial education in his or her specialty.

To generalize again, the older a surgeon is, the more likely it is that he or she is remote from his or her initial education in his or her specialty. For many decades, the typical medical student has begun his or her doctoral education at age 22 years. Only a few medical schools really encourage nontraditional students, and it is very rare for a male candidate to be admitted to medical school beyond the age of 26 years. Medical school typically lasts 4 years, so the surgeon must have started his specialty education around age 26 to 31 years, and probably closer to 26 years. Typically, surgery residency education lasts 5 years, with approximately half taking a subspecialty fellowship after residency, so the initial specialty education ends at approximately 31 to 37 years of age, probably closer to 31 years of age. The remoteness of any surgeon's initial education can be estimated as his age minus 31 years.

The lesser quantity of education and greater remoteness of education are not the most profound age-related effects. Because the chronologic era when the education was obtained differs, the content of the education differs. To consider orthopaedic surgery as an example, essentially every treatment technique taught 25 years ago has been abandoned and replaced. To give examples in two areas, the treatment of almost all traumatic fractures is different and the treatment of all degenerative joint disease is different.

Twenty-five years ago, all fractures of the femoral shaft were treated by 6 weeks in the hospital in traction followed by at least another 6 weeks in a plaster cast. Twenty years ago, there was a brief period when fractures of the shaft of the femur were treated with plate fixation. Now, almost all femoral shaft fractures are treated with locked intramedullary nailing. So a typical orthopaedic surgeon who is today 56 years old or older could not have been taught the technique of locked intramedullary fixation of femoral fractures during his or her residency education. If he or she has learned the technique, he or she learned it outside of formal education.

A similar change has affected the treatment of tibial fractures. Twenty-five years ago, almost all fractures of the tibial shaft were treated by casting. Now, nearly all are fixed with a locked intramedullary nailing. Twenty-five years ago, it was heresy to place metallic fixation hardware in an open fracture any sooner than approximately 1 week after the injury. To do so was thought to invariably cause infection. Now, open fractures are fixed using hardware everywhere in the nation, every night, as soon as possible after the injury.

Thirty-five years ago, prosthetic arthroplasty was unheard of. Treatment of arthritis was by osteotomy or tenotomy-myotomy. Twenty-five years ago, arthroplasty of the hip was established, and arthroplasty of the knee followed closely behind. At that time, the saw cuts were made by the surgeon by hand and eyeball. Eyeball alignment of 
knee replacement resulted in many a malaligned knee. Since that time, all hip and knee replacement systems include complex and precise jigs to guide the saw blade while cutting the bone, and problems of wrong limb length and joint alignment are in the past. So a typical orthopaedic surgeon who is today 66 years old or older could not have been taught anything at all about joint replacement during his or her formal residency education, and a present surgeon older than approximately 40 years old could not have been taught modern joint replacement techniques during his or her formal residency education.

Treatment methods in the following list of orthopaedic conditions have been completely changed in the last 25 to 35 years: (1) fixation of fractures of all long bones; (2) fixation of fractures of the flat bones; (3) fixation of fractures of almost every joint, except the hip; (4) arthroscopic treatment of cartilaginous and ligamentous conditions of all major joints; (5) treatment of fractures and deformities of the spine; (6) treatment of pediatric foot deformities; (7) treatment of cancers without amputations; and (8) reattachment of severed thumbs, fingers, hands, and arms.

All surgical specialties have had similar turnover of treatment methods. In the field of general surgery, laparoscopy is progressing to replace open abdominal surgery. "In surgery, ... [c] hanging skills are required. The cut-feelstitch needed for an open surgery is quite different than those needed for operating on images on a television screen as is the case with laparoscopic surgery" [2].

Only a few research projects have studied the relationship between surgeon age or remoteness of surgeon education and the results of surgery. O'Neill et al. [17] studied the relationship between years since licensure of the surgeon (and other factors) and death, or complications short of death, for the procedure of carotid endarterectomy. The study included 12,725 operations in 284 hospitals. Increased years since surgeon licensure predicted increased rate of patient death but did not predict nonfatal complications. Another study reported no physician age-related difference in treatment of certain cancers [12], but the study was methodologically flawed; this study depended on self-reporting of practice behaviors and was subject to severe selection bias with less than $37 \%$ of those surveyed answering. In a similar study of members of the American Society of Plastic and Reconstructive Surgeons, 395 surgeons provided evaluable responses to a survey about their practice patterns pertaining to recurrent melanoma. This study found definite age-related differences in the ordering of certain tests to detect the possible spread of the cancer in patients who had an operation to remove their tumor. Older surgeons ordered the most modern imaging studies (positron emission tomography [PET] scans) to a greater extent, but the older surgeons also ordered more of a chemical test no longer believed to be helpful (5-S-cysteinyl dopa).
Younger surgeons ordered fewer PET scans and more chemical tests currently believed to be helpful (selected serum transaminases). It is not possible to say that the methods used by either the older or younger surgeons are actually preferable [14].

In a meta-analysis, Choudhry et al. [6] searched the medical literature for evidence of a relationship between physician age and quality of medical care. They initially found 245 potentially helpful articles, but after rejecting the irrelevant, they ended up with 59 articles for study. Their study did not concentrate on surgeons; all types of physicians were included. Of the articles found, half (52\%) reported all measures of quality of care declining with increasing physician years in practice. For the other half of the articles, the results were less clear, but only $7 \%$ reported increasing quality of medical care with increasing years in practice.

\section{Experience versus Skill}

Closely related to the problem of remoteness of education is the need to maintain old skills, develop new skills, and grow through experience. Experience alone can substitute for a lot of mechanical skills. It is generally agreed that the deterioration of purely physical skills begins near the end of the third decade of life (around age 28). Cognitive skills diminish later. Yet it is widely agreed that most surgeons reach their peak of overall performance around the second half of the fifth decade (45-50 years of age). What appears to be happening is that, for more than two decades, growing experience can and does more than compensate for diminishing physical skills.

An experienced surgeon may have seen many patients with a certain diagnosis. If a patient comes anew with this diagnosis, the experienced surgeon, having seen it so often before, will far more easily and accurately recognize the problem than a novice would. An experienced surgeon will have seen patients with many, many diagnoses. When a patient with a rare condition comes, the experienced surgeon, having seen so many conditions before, will have a far better chance of recognizing the problem than a novice would. The novice may learn in theory how patients should respond to treatment, whereas the experienced surgeon will have learned in fact how actual patients have responded to operations actually performed on them. The theory and the practice may not coincide.

\section{Physical Decline}

Greenfield and Proctor [10] identified vision, hearing, motion, and dexterity as physical attributes of a surgeon 
that inevitably decline with age. Reaction time, the time needed to move in response to a stimulus, has been found to decline only slowly. Rovit [18] lists other physical attributes that decline with age. "Maximum strength is generally achieved during the third decade of life, with a $25 \%$ loss of strength by age 65 years. ... As we age, visual acuity and accommodation decrease in association with hardening and yellowing of the lens [of the eye]... and pupillary shrinkage. Optimal performance requires...100\% more [illumination] in workers older than 55 years" [18].

\section{Cognitive Decline}

Trunkey and Botney [19] have developed a series of tests, together named the "MicroCog," designed to detect "impaired competence occurring late in a physician's career." The tests measure "reactivity, attention, numeric recall, verbal memory, visiospatial facility, reasoning, and mental calculation" [19]. According to the overall MicroCog scores, at all ages, physicians (not necessarily surgeons) perform better than nonphysicians, but even physicians by age 75 lose $25 \%$ of their starting score. The decline is very rapid by age 60 . The data also show a decline in overall MicroCog scores for older physicians (not necessarily surgeons), both working and retired. At all ages, but especially at older ages, retired physicians score lower than working physicians.

Trunkey and Botney [19] assert that the MicroCog has been validated, but they are no more than partly correct. The subtests of the MicroCog arguably should measure surgeon competency and skills. For example, surely a better score on reaction time would be a good thing for a surgeon; surely a good score on "visiospatial facility" would be a good thing for a surgeon. Indeed, the scores on the MicroCog do decline with age. However, there has not been any showing that a good score on the MicroCog correlates with good performance of surgery or that a low score on the MicroCog correlates with incompetency or lack of skill. These correlations may exist in fact, but they have not been demonstrated to exist.

The game of chess is not surgery. However, the cognitive part of the game has some parallels to surgery. Both involve making decisions in a complex system. In both, the system is too complex to be thoroughly analyzed. In both, there are adverse consequences for making suboptimal decisions, and there are rewards for choosing well. The "chess rating" is a well-defined, objective scoring system based on actual wins and losses and based on the scores of opponents beaten and beaten by. The decline after approximately age 35 is similar to the declines seen in the MicroCog scores. Interestingly, the peak performance seems to be from approximately age 28 to 45 or 50 years [19].
Greenfield and Proctor [10] identify (1) the ability to focus attention; (2) the ability to process and correlate information; and (3) native intelligence as cognitive attributes of a surgeon that must decline with age. In a study of 468 Australian and New Zealand psychiatrists (none surgeons) aged 55 years and over who were queried, 281 responded to a survey of the influences on and of the effects of age and retirement. Of these, 223 were still working full time after age 55. Of these 223, 22\% believed age conferred greater credibility and respect, $21 \%$ a more mature life perspective, and $49 \%$ greater actual confidence and competence. However, $27 \%$ reported fatigue interfering with work, $12 \%$ difficulty keeping up with advances in knowledge, and $10 \%$ poor memory [7].

Breast reconstruction immediately after extirpative surgery for cancer is a relatively modern development. Callaghan et al. [5] surveyed 498 specialized breast surgeons in the United Kingdom. More than three-fourths answered. They reported "older surgeons were significantly less likely to perform immediate reconstruction $(\ldots$ Odds ratio $=5.18)$, and were significantly more likely to believe that immediate breast reconstruction has disadvantages" [5].

Heck et al. [11] studied 563 patients from Indiana who had surgical replacement of a knee. Patients were followed for a minimum of 2 years. In the end, the study group consisted of 291 patients (330 knees). Younger surgeon age was correlated with fewer complications [11].

Wang and Winfield [21] surveyed the 1450 members of the North Central section of the American Urological Association about their use of laparoscopic surgery. Laparoscopy is believed to reduce bleeding, reduce scar formation, reduce pain, and reduce the patient's time to recovery. Approximately half (49\%) of the surgeons responding to the survey did not do laparoscopy at all, and only $21 \%$ used laparoscopy in more than $5 \%$ of their practice. Only $15 \%$ believed they were adequately trained in residency to perform laparoscopy. "There was an inverse correlation between time in practice and amount of laparoscopy performed" [21]. Ahmad et al. [1] confirmed a relationship between older surgeon age and a predilection against the use of laparoscopy. Neumayer et al. [16] found surgeon age older than 45 years heralded an increased rate of recurrence (failure of the repair) in laparoscopic hernia repairs.

\section{Why Is the Surgeon the Last to Know When It Is Time to Retire?}

“As long ago as 1792, Dr. Thomas Percival addressed the duty of physicians to retire..., stating that physicians should consider retirement when...experience[ing] the 'wonted confidence of their peers.' Medicine is a 
fiduciary profession, and it is the duty of each practitioner to give up the task when his or her skills have deteriorated. How to recognize this point may constitute a significant problem" [18].

"Honest, balanced surgeons apprehensively await...warnings [that say], 'This was not an impeccable performance!' ... And when [the warnings] arrive, they become demons of the night. At first, while you are sleepless, staring into the dark, they will be a secret that you will keep from your wife at your side; but soon she will know" [4].

Rovit [18] has put forth three reasons why surgeons resist retiring: (1) lack of self-esteem; (2) fear of death; and (3) resistance to change. The layperson cannot easily understand how lack of self-esteem can possibly be a factor in a surgeon's reasoning. The external persona exhibited by the typical surgeon is one of utmost confidence. For the most part, this is an artifice. Merely to get the job done, it is necessary for a surgeon to put on a show of confidence to the patient and the patient's family. The placebo effect is strong, both positively and negatively. There will be a strong tendency for a patient to fail to improve if he or she perceives his or her surgeon to lack confidence in the procedure or in his or her own surgical skills. In my opinion, surgeons tend to be very introspective and selfcritical. They analyze their failings alone or in small groups of trusted colleagues. A good surgeon is always only one or two bad operations away from a complete loss of selfrespect. Finally, many surgeons see their own value in performing surgery. If a surgeon stops doing surgery, he or she runs a risk he or she will no longer value him- or herself. On the other hand, some have little insight into when their skills decline.

A large fraction of surgeons fear death and disease. There is a common saying among surgeons, "Surgery is for patients, not for surgeons." When expounded, this means patients are those who need surgery, surgeons do not need surgery, and moreover, surgeons should not have surgery. Some believe surgeons enter the occupation of surgery out of a need to struggle with and defeat death and disease. When a surgeon stops doing surgery, he or she becomes more like a patient, susceptible to death and disease. This fear is heightened in that the decision for retirement comes at the same time that the surgeon's physical and cognitive skills are waning, and surely, death cannot follow too far behind. So, the decision to retire resembles the decision to die.

Resistance to change is an impediment to the decision to retire. It would be very difficult to imagine two occupations more different than that of a busy surgeon as compared with that of a retiree. How different must it be to arrange flowers to impress one's wife compared with rearranging internal organs to save the life of a deathly ill patient? How different can it be to arrive at work at 6 am to bark limb- preserving orders to a highly educated and highly paid staff who execute the orders instantly compared with sleeping in late so as not to wake the dogs and make them bark? It must be very frightening to embark on such a large change not knowing if one can tolerate the new circumstances and knowing that the decision to retire is, for all practical purposes, irrevocable.

\section{Assuring Competence in Surgery}

There is no uniform or widespread method to assure competence of surgeons. Each state government has a mechanism for the discipline or suspension of so-called incompetent physicians. These mechanisms are often put to good use in cases of substance abuse, financial fraud and abuse, and sexual impropriety with patients. However, there is no evidence that such mechanisms work to identify or intervene in cases of the gradual failing of surgeons' competence resulting from aging.

Each hospital has a duty to recruit and retain only competent physicians, and this certainly includes surgeons. However, there is no evidence that hospitals are able to detect a gradual decline in surgeon competence. Error alone cannot be used to determine incompetence, because all surgeons err occasionally. Furthermore, error is often a failure of the treatment system and not necessarily the result of a single person [19]. In some cases, when a hospital knows it has a problem with a bad surgeon, it will not take action for financial reasons. In one illustrative case, an attorney had finished defending a hospital against a malpractice claim based on the agency of a surgeon, and he noticed that the same surgeon had been named in more than 30 malpractice suits. The attorney wrote to warn the hospital president that he had a "bad doctor" on staff and that he should do something. The hospital president said, "Don't ever write me anything like that again. That surgeon's business is all that keeps our surgical wing afloat!" [3].

The closest that surgery now gets to an assurance of competence is individual certification by one of the boards of the American Board of Medical Specialties. Each surgical specialty has its own certifying board. Each specialty board has different, but similar, requirements for a surgeon to become certified. Typical requirements are: (1) degree from an accredited medical school; (2) medical licensure in a state; (3) completion of an accredited postgraduate specialty residency; (4) written declaration by the Residency Program Director of attainment of academic, procedural, and ethical competence; (5) passage of a written examination; (6) 2 years of postresidency practice in a single geographic location with no disciplinary action or peer complaint; and (7) passage of a battery of oral examinations. Before 1986, orthopaedic board certification endured 
for the life of the surgeon. Since then, certification has been time-limited, and now orthopaedic surgeons must recertify every 10 years or lose certification.

The initial certification is difficult to achieve, and it is very unlikely that a surgeon with a major impairment or incompetency could achieve certification. Indeed, the overall failure rate for graduates of domestic medical schools is approximately $10 \%$ (30\% for international graduates), even allowing for multiple attempts at the examinations. Some large hospital systems are beginning to require board certification within a certain time (4 years is common) after the end of residency education. Smaller hospitals and rural hospitals are generally not now requiring board certification to gain staff privileges.

As good as the initial certification process is at assuring competency, the recertification process is very much weaker. To recertify, the surgeon must show evidence of a certain minimum number of hours of continuing medical education and take a test. Using orthopaedic surgery as an example, three tests are available: (1) a written test, very much like the initial written certification test; (2) an oral examination with questions based on the surgeon's own cases; and (3) a practice inventory. It is telling that no orthopaedic surgeon who has ever attempted to recertify has ultimately failed to do so (some have taken a test more than once but ultimately passed; Patsy Furr, Executive Secretary, American Board of Orthopaedic Surgery, personal communication). This means one of the following three propositions is true: (1) all surgeons are remaining competent; (2) surgeons lacking competency are choosing not to attempt recertification; or (3) the scores necessary to recertify are set too low. In any case, the recertification process can test knowledge and may test cognition, but it cannot test manual dexterity, coordination, or reaction time. Whatever the reason, it is apparent the present recertification process is not able to deal with the problem of diminishing skills in the aging surgeon.

Before 1993, the American College of Surgeons Board of Governors' Committee on Physicians' Health was charged with the task of studying and making recommendations about the admittedly "controversial issue of credentialing the aging surgeon" [15]. This seemed to be a promising step in the right direction. However, a search of the literature has located no evidence of any publication of the results of this charge in the decade and a half since the committee was so charged.

\section{Assuring Competence in Commercial Aviation}

Commercial airline pilots are not permitted to act as pilotin-command past a certain age. The maximum age limit to act as pilot in command in Europe and the United States is
65 years. On both continents, pilots under the maximum allowable age are subjected to frequent medical examinations and performance retesting to assure retention of a safe level of skills.

Trunkey and Botney calculated that if surgeons failed a hypothetical medical test at the same rate that US commercial pilots fail their semiannual medical tests, then 39 surgeons per year would lose privileges in the United States attributable solely to medical problems [19]. Admittedly, their calculation is a gross oversimplification, and an argument can be made that they are very high or very low in their estimate, but the fact remains that some surgeons become incompetent as a result of loss of capabilities with aging; there presently is no systematic method to accurately identify such individuals, and surely some must be continuing to practice.

\section{Recommendations}

The possible methods to prevent decreasing surgical skills resulting from age from becoming a major risk to patients naturally fall into (1) mandatory measures (external forces that compel surgeons to cease operating) and (2) education (increasing surgeon and societal awareness of this potential problem and encouraging surgeons to use heightened insight into their own limitations). Neither method is effectively in use in this nation at this time, and both approaches have substantial drawbacks.

\section{Mandatory Measures}

For many decades, federal laws forbidding age discrimination have made it impossible to mandate surgeon retirement based mainly on age and have made it impossible for hospitals and other medical facilities to withdraw surgical privileges based solely on age. Consider the following: The Age Discrimination in Employment Act (ADEA), 29 U.S.C. $§ 621$, et seq, "Congressional statement of findings and purpose (a) The Congress hereby finds and declares that-(1) ...older workers find themselves disadvantaged in their efforts to retain employment...; (2) the setting of arbitrary age limits regardless of potential for job performance has become a common practice...; (3) ...; (4) ... . (b) It is therefore the purpose of this chapter...; to prohibit arbitrary age discrimination in employment; ... ."

For employed surgeons, use of the surgeon's chronologic age as a determinant of when he or she must retire is clearly in violation of the ADEA.

Paul H. Gates v John H. Flood, 785 NE2d 1289, (2003): "It is no defense to a discharge based solely 
on age that the employer mistakenly believed that age was a bona fide occupational qualification (BFOQ) for the employee's job."

Zipp, EK: Proving that Discharge was because of Age, for Purposes of Age Discrimination in Employment Act (29 USC $\S \S 621$ et seq), 58 ALR Fed 94. "When plaintiff alleges unlawful discharge based on age, [a] prima facie case requires proof that (1) plaintiff was a member of protected class, ie, was 40 years of age or older, (2) that plaintiff was discharged, (3) that plaintiff was qualified for [the] job, and (4) that plaintiff was replaced by [a] sufficiently younger person to create [an] inference of age discrimination."

When surgeon age is the actual determinant of retirement from employment, an unassailable prima fascia case should be easy to make.

Even when there is no employer-employee relationship such as in a corporation-shareholder relationship in which the shareholder is a working surgeon, the definition of "employee" for purposes of ADEA has been broadened to give the working shareholder protection from discrimination based on age.

Betty Gorman v North Pittsburgh Oral Surgery Associates: LTD. (1987). 664 FSupp 212 "Employee who was allegedly forced to retire from professional oral surgery corporation filed suit under Age Discrimination in Employment Act against corporation, which moved for summary judgment. The District Court, Ziegler, J., held that: (1) doctors who were shareholders in corporation were "employees" under ADEA; (2) corporation was "employer" as it employed 16 full-time and six part-time employees during period in question; and (3) genuine issue of material fact, as to whether employee had met burden of showing that proffered reasons for termination were pretext for discrimination, precluded summary judgment."

In cases in which there is no employment relationship at all, there are not many cases to give precedential guidance. However, it appears that "unequal accommodation, based on age discrimination" should be an effective cause of action under many state constitutions and under the federal constitution. It seems quite clear then that any private action to mandate retirement of surgeons or curtailment of surgical privileges based solely or mainly on age will be found unlawful when contested.

In the United Kingdom, the law is different. There, at age 65 years, surgeons must stop performing surgery in the Public Health Service. There, at age 70, a surgeon must retire also from private practice, ending his or her surgical career. There is controversy over the issue of whether an arbitrary age limit is a good way to decide when a surgeon must retire, but the system has been pretty well accepted. Many surgeons get greater satisfaction, and certainly greater recompense, from their private practice than they do from the Public Health Service, and although many resent having to depart the Public Health Service at age 65, many are mollified by being allowed to continue their private practice to age 70 .

The law concerning aged surgeons in the United States could be changed. In the field of aviation, pilots and first officers (copilots) for the major airlines may not, by statute, act as pilot or first officer after age 65 years. There is no provision for any exception to this law. Every challenge to this law has failed. It is obvious these pilots are not being given equal protection under that law, but the inequality is being imposed on them to further a compelling state interest, and therefore, the unequal treatment of pilots based on their age has always been found not unconstitutional. It has been shown again and again that the physical capabilities of pilots (and everyone else) decline with age. Protecting the safety of the flying public is a compelling state interest. To date, there has been no showing that there exists any test or battery of tests that can be applied in a practical sense to pilots to ascertain which pilots are safe to fly at age older than 65 years. As such, mandatory retirement of commercial airline pilots at age 65 remains the law in the United States.

Congress could enact similar legislation concerning surgeons. Protecting the safety of patients could be a substantial state interest. To date, there has been no showing that there exists any test or battery of tests that could be applied to surgeons to ascertain which retain their surgical skills with aging. Mandatory retirement of surgeons at an arbitrary age could become the law in the United States. There is presently no groundswell of enthusiasm to accomplish this, however.

Rovit [18] summarized some of the difficulties in identifying when a surgeon has lost skills to a degree that he or she should stop operating. First, Rovit wrongly asserts that one often performs surgery under the observation of one's colleagues [18]. To the extent that he intends "colleagues" to include "other surgeons," he is incorrect. It is distinctly rare to have more than one attending surgeon in an operation. There may be surgeontrainees, nurses, and technicians in the operating room, but almost never two attending surgeons. So the opportunity for one attending surgeon to critique the performance of another is almost nonexistent. Furthermore, trainees, nurses, and technicians are not empowered or encouraged to officially criticize the technical skills of the attending surgeon. Gross negligence may be observed and reported, but anything less will be missed, and small lapses in 
judgment are far more likely than gross deviations, especially early in the surgeon's decline.

Hospitals universally have quality assurance departments and quality improvement activities. These activities are able to detect grossly aberrant outcomes such as death and surgical infection. However, such activities are completely unable to detect important substandard outcomes such as less pain relief than should have been possible, less restoration of patient function than should have been possible, and so on. These types of criteria are impossible for a hospital-based activity to monitor. It would be possible to invent a system of proctoring of the operations of an elder surgeon. However, colleagues, especially former trainees of the proctored surgeon, might be too deferential, whereas competitors might be too harsh.

Trunkey and Botney [19] take the opposite view. They recommend testing conducted by the American Board of Surgery under the supervision of the American College of Surgeons. They do not consider the fact that there is no agreement on what skills to test or how to test them.

" $[I]$ is clear that we need better data on the performance of aging surgeons... . Both cognitive and functional test results should be evaluated under controlled circumstances... . Above all, we need to remove the stigma associated with retirement and construct ways for productive members of our society...to retain their self-esteem as they enter the final chapters of their career" [8].

Some commentators have recommended legislation to protect the public from aging surgeons. Baratham has suggested a rigid, fixed upper age limit as the only criterion for a statute terminating the operating privileges of the elder surgeon [2]. In advocating such a rigid standard, he acknowledges that whatever age is chosen, some would have been competent past that age, and some would have lost necessary skills before that age. However, he believes a rigid cutoff would be fairer and more effective than either peer review or relying on the surgeon's own insight.

\section{Education and Appeal to Conscience}

Being a surgeon is perhaps the most privileged of all occupations. The sick, the pained, and the frightenedpatients and their families-hand over in trust their most intimate matters of life and limb, life and death, vigor and disease. To be so burdened and simultaneously so honored is a privilege like no other. One reason surgeons may persist in their craft after their skills are gone is there is no other activity that is nearly so rewarding. R. M. Kirk points out this problem and suggests an acceptable substitute for surgery would be teaching [13]. Mr. Kirk does not suggest continuing in teaching technical surgery to registrars (British for "residents"). Rather, he suggests retired surgeons could offer valuable teaching in four areas: (1) preclinical teaching to medical students, particularly anatomy and physiology; (2) clinical teaching to medical students, particularly coaching them in learning to take a patient history and perform a physical examination; (3) acting as an experienced surgical assistant to a registrar in training; and (4) teaching basic surgical skills in workshops. The common thread connecting these four areas is they all require a lot of time, pay little or nothing, and place the teacher in a position where his or her actions cannot cause harm. Perhaps if the elder surgeon realized there are ways to continue making valuable contributions after retirement from performing surgery, he or she might be more inclined to retire before his or her skills are gone.

It is apparent that surgeons are not aware that each should be planning retirement rather than ignoring retirement. Greenfield and Proctor [9] conducted a survey of the members of the American Surgical Association. Of 882 members surveyed about their attitudes toward the inevitable end of their careers, approximately three-fourths responded (659 of 882). Fewer than half of those answering had made any retirement plans at all, and three-fourths of those planned to "retire" to medical activities. Of surgeons aged younger than 50 years, only $6.5 \%$ had made any plans for what they would do after retirement. Most of the responders older than 70 years old had retired, but strikingly, of surgeons aged older than 70 years who had not yet retired, only $40 \%$ had made any retirement plans, and more than half were performing operations at a rate self-estimated to be their "normal" workload [9]. The lack of retirement planning and the high rate of continuing to perform operations suggest at least the possibility that these surgeons are lacking in insight. Another explanation, although one that should not be accepted without more evidence, is that these elite-level members of the American Surgical Association are so superior that they may safely continue performing surgery without the need to consider retirement.

In 1990, Rovit [18] conducted a nonscientific survey of 29 distinguished retired neurosurgical colleagues and friends to inquire of their thoughts about retirement and reasons for retirement. He received 22 answers. Half of the 22 addressed the question of why each retired. Half of those wanted to retire "at the top of their game" [18], before their abilities declined, whereas the other half retired when demoted from department chairmanship as a result of age. Of the 22, half continued in nonsurgical medical practice, usually limited to part-time work. The other half performed a wide variety of hobbies or charity work. All who responded expressed positive thoughts about the decision to retire.

Virshup and Coombs [20] surveyed 238 retired physicians in Los Angeles County about their adjustment to 
retirement, receiving a $42 \%$ response. Seventy-five percent of the respondents enjoyed retirement. Forty-nine percent found life was improved after retirement. Only 7\% were definitely unhappy, most of those for reasons of diminished intellectual stimulation, diminished income, and missing colleagues [20].

The American College of Surgeons Board of Governors' Committee on Physicians' Health in 1993 conducted a survey of retired members of the College on their attitudes toward retirement [15]. The survey questionnaire was sent to 2132 members who had retired between 1983 and 1988, and 40\% (850 members) responded. Reasons for retirement included: (1) an adverse malpractice experience; (2) "just wanted to retire"; (3) "age"; and (4) "fear of loss of competence." Age was the third most common reason given, whereas loss of competence was far down the list. Concerning overall satisfaction, the majority (47\%) found retirement about as good as expected, many (42\%) found retirement better than expected, and a few (9\%) found retirement worse than expected. The unsatisfied retirees listed "poor health, insufficient income and... "nothing to do" "as the reasons for their dissatisfaction. The average gross income declined $36 \%$ on retirement, but $90 \%$ of the survey responders believed their income was at least adequate. When asked what would have made retirement better, the majority answers were: (1) "saved/invested/earned more money"; (2) "planned better/earlier"; and (3) "spent more time with family." In fact, $11 \%$ of these retired surgeons had made no preretirement plans at all; 59\% had instituted financial retirement plans; and $9 \%$ had taken on new hobbies, new interests, or a new occupation. This study reported retired surgeons who had taken up postretirement activities outside of medicine were more likely to be satisfied than those who remained in medicine in some nonsurgical capacity. Finally, in noting that poor health was associated with dissatisfaction, the authors concluded that preretirement planning should include measures aimed at better health: (1) controlling weight and diet; (2) reducing or eliminating smoking, drinking, and illicit drugs; (3) exercising; and (4) practicing safe sex. Their survey did not demonstrate that these behaviors would actually improve health or increase postretirement satisfaction, but the advice rings true.

\section{Summary: There Is a Problem!}

Anecdotes suggest many surgeons lack insight into the gradual degradation of their own skills. Research has repeatedly documented that age causes deterioration in physical and cognitive performance. In general, older surgeons have had less education, at a more remote time, which is less applicable to present technology. There is weak evidence from clinical studies that links older surgeon age with more complications and less adoption of modern technology. Other occupations (aviation) have statutorily mandated retirement ages. Other nations (United Kingdom) have statutorily mandated retirement ages for surgeons. There is no present outcry for a statutory-mandated retirement age for surgeons in the United States. Various American surgical societies have been coming to grips with this question for more than a decade now, but there has been no effective progress toward a solution. Educating surgeons to three facts may reduce the problem: (1) The surgeon's skills will fade; (2) planning may make retirement quite satisfying; and (3) retirement does not have to bring the loss of all self-worth and an imminent death. Finally, educating surgeons, colleagues of surgeons, hospital administrators, patients, and the plaintiff's bar may bring about changes that will induce surgeon retirement at an appropriate time.

Acknowledgments I thank Lazar J. Greenfield, MD, for forcing me to think of this problem for the past 20 plus years.

\section{References}

1. Ahmad S, Lettsome L, Schuricht A. The role of laparoscopy in the management of groin hernia. JSLS. 1998;2:169-173.

2. Baratham G. 11th Chapter of Surgeons Lecture - the art of letting go. Ann Acad Med Singapore. 2001;30:89-92.

3. Boothman R. Wayne State University Law School Lecture; Oct 27, 2005; Detroit, MI.

4. Bunkin IA. When does a surgeon retire? JAMA. 1983;250:757758.

5. Callaghan CJ, Couto E, Kerin MJ, Rainsbury RM, George WD, Purushotham AD. Breast reconstruction in the United Kingdom and Ireland. Br J Surg. 2002;89:335-340.

6. Choudhry NK, Fletcher RH, Soumerai SB. Systematic review: the relationship between clinical experience and quality of health care. Ann Intern Med. 2005;142:260-273.

7. Draper B, Winfield S, Luscombe G. The older psychiatrist and retirement. Int J Geriatr Psychiatry. 1997;12:233-239.

8. Greenfield LJ. Farewell to surgery. J Vasc Surg. 1994;19:6-14.

9. Greenfield LJ, Proctor MC. Attitudes toward retirement. A survey of the American Surgical Association. Ann Surg. 1994;220:382389; discussion 387-390.

10. Greenfield LJ, Proctor MC. When should a surgeon retire? $A d v$ Surg. 1999;32:385-393.

11. Heck DA, Robinson RL, Partridge CM, Lubitz RM, Freund DA. Patient outcomes after knee replacement. Clin Orthop Relat Res. 1998;356:93-110.

12. Johnson FE, Novell LA, Coplin MA, Longo WE, Vernava AM, Wade TP, Virgo KS. How practice patterns in colon cancer patient follow-up are affected by surgeon age. Surg Oncol. 1996;5:127-131.

13. Kirk RM. The retired surgeon: a potential teaching resource. Ann $R$ Coll Surg Engl. 1997;79(Suppl):73-74.

14. Margenthaler JA, Johnson DY, Virgo KS, Fosko SW, Chan D, Goshima K, Handler BS, Johnson FE. Evaluation of patients with clinically suspected melanoma recurrence: current practice patterns of plastic surgeons. Int J Oncol. 2002;21:591-596. 
15. Miscall BG, Tompkins RK, Greenfield LJ. ACS survey explores retirement and the surgeon. Bull Am Coll Surg. 1996;81:18-25.

16. Neumayer LA, Gawande AA, Wang J, Giobbie-Hurder A, Itani KM, Fitzgibbons RJ Jr, Reda D, Jonasson O. Proficiency of surgeons in inguinal hernia repair: effect of experience and age. Ann Surg. 2005;242:344-348; discussion 348-352.

17. O’Neill L, Lanska DJ, Hartz A. Surgeon characteristics associated with mortality and morbidity following carotid endarterectomy. Neurology. 2000;55:773-781.
18. Rovit RL. To everything there is a season and a time to every purpose: retirement and the neurosurgeon. $J$ Neurosurg. 2004;100:1123-1129.

19. Trunkey DD, Botney R. Assessing competency: a tale of two professions. J Am Coll Surg. 2001;192:385-395.

20. Virshup B, Coombs RH. Physicians' adjustment to retirement. West J Med. 1993;158:142-144.

21. Wang DS, Winfield HN. Survey of urological laparoscopic practice patterns in the midwest. J Urol. 2004;172:2282-2286. 